\title{
"One-stop shop" spectral imaging for rapid on-site diagnosis of lung cancer: a future concept in nano-oncology
}

This article was published in the following Dove Press journal:

International Journal of Nanomedicine

21 November 2013

Number of times this article has been viewed

\author{
Kaid Darwiche' \\ Paul Zarogoulidis ${ }^{1,2}$ \\ Leslie Krauss ${ }^{3}$ \\ Filiz Oezkan' \\ Robert Fred Henry \\ Walter ${ }^{1,4}$ \\ Robert Werner ${ }^{4}$ \\ Dirk Theegarten ${ }^{4}$ \\ Leonidas Sakkas ${ }^{5}$ \\ Antonios Sakkas 5 \\ Wolfgang Hohenforst- \\ Scmidt ${ }^{6}$ \\ Konstantinos Zarogoulidis \\ Lutz Freitag' \\ 'Department of Interventional \\ Pneumology, Ruhrlandklinik, West \\ German Lung Center, University \\ Hospital, University Duisburg- \\ Essen, Essen, Germany; ${ }^{2}$ Pulmonary \\ Department, Oncology Unit, \\ G Papanikolaou General Hospital, \\ Aristotle University of Thessaloniki, \\ Thessaloniki, Greece; ${ }^{3}$ CytoViva, \\ Inc, Auburn, AL, USA; ${ }^{4}$ Institute of \\ Pathology and Neuropathology, \\ University Hospital of Essen, \\ University of Duisburg-Essen, Essen, \\ Germany; ${ }^{5}$ Pathology Department, \\ G Papanikolaou General Hospital, \\ Thessaloniki, Greece; 6 II Medical \\ Department, Coburg Regional Clinic, \\ University of Wuerzburg, Coburg, \\ Germany
}

Correspondence: Paul Zarogoulidis Pulmonary Department, G Papanikolaou General Hospital, Aristotle University of Thessaloniki,Thessaloniki, Greece Fax +30 21 30992433

Email pzarog@hotmail.com
Background: There are currently many techniques and devices available for the diagnosis of lung cancer. However, rapid on-site diagnosis is essential for early-stage lung cancer, and in the current work we investigated a new diagnostic illumination nanotechnology.

Methods: Tissue samples were obtained from lymph nodes, cancerous tissue, and abnormal intrapulmonary lesions at our interventional pulmonary suites. The following diagnostic techniques were used to obtain the samples: endobronchial ultrasound bronchoscopy; flexible bronchoscopy; and rigid bronchoscopy. Flexible and rigid forceps were used because several of the patients were intubated using a rigid bronchoscope. In total, 30 tissue specimens from 30 patients were prepared. CytoViva ${ }^{\circledR}$ illumination nanotechnology was subsequently applied to each of the biopsy tissue slides.

Results: A spectral library was created for adenocarcinoma, epidermal growth factor receptor mutation-positive adenocarcinoma, squamous cell carcinoma, usual interstitial pneumonitis, nonspecific interstitial pneumonitis, typical carcinoid tumor, sarcoidosis, idiopathic pulmonary fibrosis, small cell neuroendocrine carcinoma, thymoma, epithelioid and sarcomatoid mesothelioma, cryptogenic organizing pneumonia, malt cell lymphoma, and Wegener's granulomatosis.

Conclusion: The CytoViva software, once it had created a specific spectral library for each entity, was able to identify the same disease again in subsequent paired sets of slides of the same disease. Further evaluation of this technique could make this illumination nanotechnology an efficient rapid on-site diagnostic tool.

Keywords: lung cancer, endobronchial ultrasound, spectral imaging, diagnosis

\section{Introduction}

There are efficient nonspecific chemotherapeutic agents and new targeted therapies currently available for the treatment of cancer. ${ }^{1-5}$ However, myelotoxicity remains an adverse effect that clinicians have to confront. ${ }^{6,7} \mathrm{New}$ localized therapies are also being explored along with conventional treatments for advanced lung cancer. ${ }^{8-14}$ Resistance to nonspecific cytotoxic agents and novel targeted therapies has already been observed. ${ }^{15}$ Therefore, early diagnosis and treatment of lung cancer remains the best option for prolonged survival. ${ }^{16}$ New biomarkers are necessary for early diagnosis of lung cancer. ${ }^{17,18}$ The autofluorescence bronchoscope technique and biomarkers from endobronchial tissue samples are also being used for early diagnosis of the disease. ${ }^{18,19}$ Lung cancer staging has recently been re-evaluated and a new system has been proposed. ${ }^{20-25} \mathrm{~A}$ new pathologic classification has been suggested for correct evaluation of the different molecular characteristics of the disease, along with patient survival. ${ }^{26-30}$ Currently, there are many tools available for staging, and 
these can be summarized as those using a display application (eg, 18F-fluorodeoxyglucose positron emission tomography/ computed tomography, mini ultrasound, bone scan $)^{31,32}$ and those used for biopsy (eg, endobronchial ultrasound bronchoscopy, flexible bronchoscopy, rigid bronchoscopy)..$^{18,33-35}$ The technique used along with the method used for pathologic evaluation of the tissue specimen determines how efficiently the disease is identified. Additional methods for enhancing diagnostic efficiency could include biomarkers or novel cell displays. ${ }^{18,36-56}$ We have evaluated the CytoViva ${ }^{\circledR}$ illumination nanotechnology which, apart from being a novel method of display, contains software that is able to learn and store new patterns. This method is currently being used by our department and has been shown to be efficient for identification of nonviral particles. ${ }^{57}$ Therefore, this technique is excellent for further investigation in other scientific fields. In the current work, we included tissue specimens from a range of benign diseases, including Wegener's granulomatosis, sarcoidosis, usual interstitial pneumonitis, nonspecific interstitial pneumonitis, cryptogenic organizing pneumonia, and interstitial pulmonary fibrosis.

\section{Materials and methods \\ Tissue samples}

We collected 30 tissue samples from 30 patients attending four interventional pulmonary suites at the interventional pulmonary department, Ruhrlandklinik University Hospital, which is affiliated with the University of Duisburg-Essen in Essen, Germany. Currently, our department is equipped with state-of-the-art diagnostic equipment, including flexible high definition bronchoscopy (Olympus ${ }^{\circledR}$, Japan, Tokyo), endobronchial ultrasound bronchoscopy (Olympus), mini-probe ultrasound (Olympus), and rigid bronchoscopy ( $\mathrm{Storz}^{\circledR}$, Karl Storz GmbH and Co, KG, Tuttlingen, Germany), as shown in Figures 1 and 2. We received ethical approval to use these entities because they are commonly used in our department. We also use a wide variety of flexible and rigid forceps (Figures 1 and 2). Our hospital is a center of pulmonary diagnostic excellence and is responsible not only for hospitalized patients but also for outpatients from regional hospitals. For this study, we obtained permission (Reference 2/7/13) from our investigational review board to use tissue samples only from our hospital. The patients attended the interventional pulmonary department based on their symptoms and were referred initially only with indications of possible disease. Tissue samples were obtained depending on clinical findings, and the site and characteristics of the lesions were recorded. A standard $1 \mathrm{~mm}$ glass slide with a Number 1 coverslip was

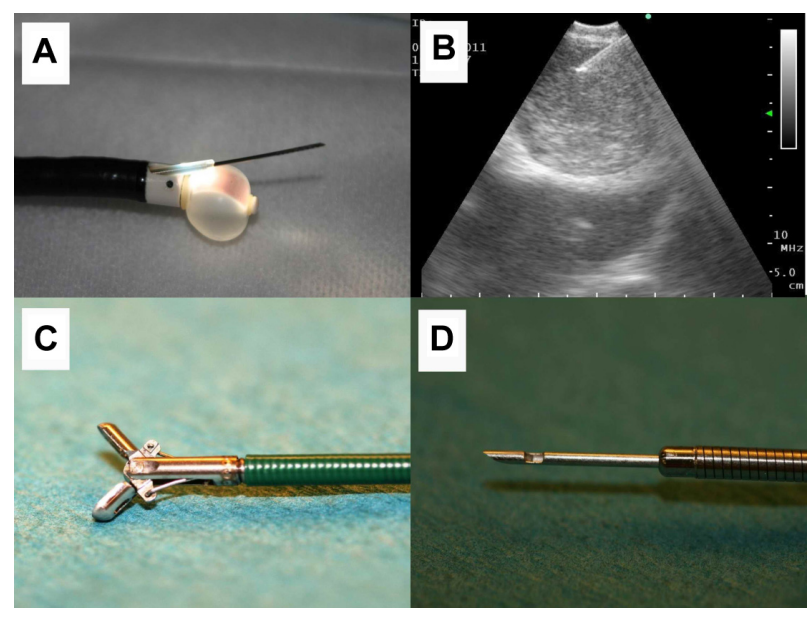

Figure I (A) Endobronchial ultrasound tip with the ultrasound balloon dilated with water for injection. The biopsy tip is out of the plastic protection probe. (B) Lymph node seen on endobronchial ultrasound, showing the biopsy tip inside the lymph node. (C) Biopsy forceps and (D) biopsy needle.

cleaned and sealed. A coverslip was used for each examination glass. The paraffin-embedded tissue specimens were sliced as thinly as possible $(10-20 \mu \mathrm{m})$. Our pathology department examined the specimens with its microscopy equipment, and based on the findings and additional help from patient files, diagnoses were made. Our pathology department has specialist expertise in the areas of diseases of the lung, thoracic surgery, and oncology. We obtained samples from patients with adenocarcinoma, epidermal growth factor receptor mutation-positive adenocarcinoma, usual interstitial pneumonitis, nonspecific interstitial pneumonitis, typical carcinoid, sarcoidosis, idiopathic pulmonary fibrosis, small cell neuroendocrine carcinoma, epithelioid mesothelioma, sarcomatoid mesothelioma, thymoma, Wegener's granulomatosis, cryptogenic organizing pneumonia, malt cell lymphoma, and squamous cell carcinoma. The tissue samples for usual interstitial pneumonitis, nonspecific interstitial pneumonitis, cryptogenic organizing pneumonia, and idiopathic pulmonary fibrosis were obtained by video-assisted thoracoscopic biopsy and not by endobronchial biopsy. These samples were obtained from our pathology archives and were again prepared from paraffin blocks. The slides were evaluated by an external pathologist (Department of Pathology, G Papanikolaou General Hospital, Thessaloniki, Greece) and sent for further evaluation using illumination nanotechnology (CytoViva Inc, Auburn, AL, USA).

\section{CytoViva technique}

Optical and hyperspectral images along with hyperspectral data were captured utilizing a research grade optical 


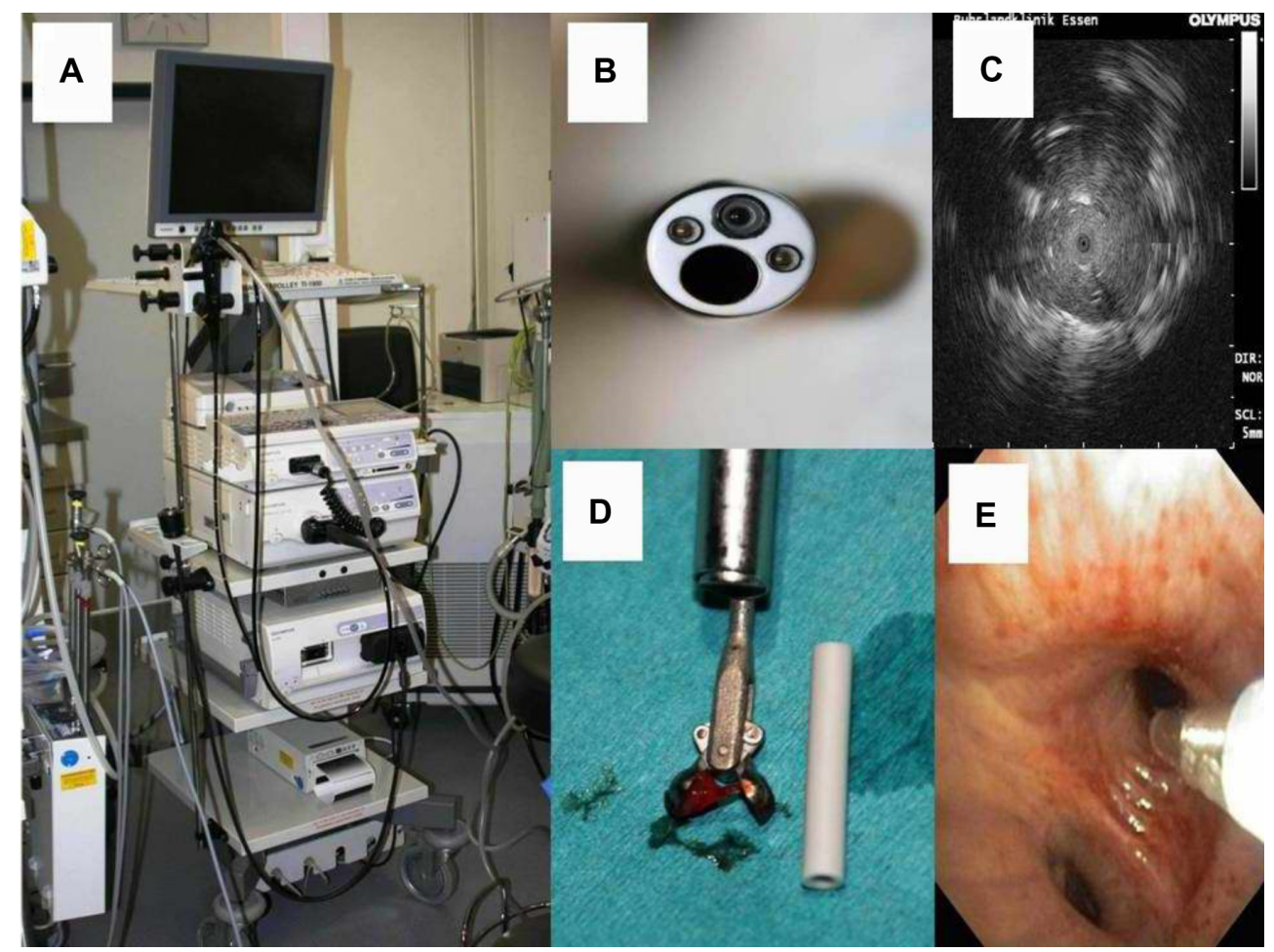

Figure 2 (A) Olympus tower, ready to use for bronchoscopy, mini-probe ultrasound, or endobronchial ultrasound. (B) Bronchoscope and (C) the "Stop effect" showing a tumor by mini-probe ultrasound. The Olympus ultrasound tip stops as it meets tumor tissue inside subsegmental alveolar tissue. (D) Biopsy forceps with tissue material and (E) Aspiration probe.

microscope equipped with the patented CytoViva advanced dark field illumination system and integrated hyperspectral imaging system.

Data from these samples were collected using transmitted light-dark field imaging. The integrated hyperspectral imaging camera collects light that is directly incident on the sample. The automated stage allows confluent imaging of a chosen field of view one line at a time. Spatial and spectral data are collected in each pixel in the line. The data cube is created by compiling pixelated lines into a single image.

Once an image has been created, analysis is undertaken to determine the spectral location of the material of interest. The particle-filter algorithm is used to collect spectral information in a consistent, repeatable pattern based on the material of interest. A spectral reference library is created by comparing the particle-filter results with a negative control sample. This removes any false positive spectral data and ensures a valid result. The spectral library is then compared with an unknown sample. The software algorithm compares each spectrum in the reference library with each spectrum in the unknown sample and then pseudocolors the matching pixels red. The final result gives spatial and quantitative characteristics based on the matching spectral signatures in the unknown sample.
CytoViva enables better resolution and detection than the optical imaging techniques traditionally used for living, fixed, or nonbiologic samples. This ability is primarily the result of exceptional contrast (high signal to noise ratio), which allows utilization of nondiffraction-limited phenomena and improved point spread function.

The resolving power of a microscope depends on the properties of the objective and the degree of coherence of the light incident upon the object. Using traditional critical illumination, a uniformly bright light source is placed close behind a diaphragm and is imaged by a condenser onto an object plane of a microscope objective. The light source is focused on the object. With traditional Koehler illumination, a converging (collimating) lens is placed close to the diaphragm and forms an image of the source light in the focal plane of the condenser, which includes a condenser diaphragm. Rays from each light source point then emerge from the condenser as a parallel beam. The light source is focused on an aperture of the condenser. With CytoViva, complete Koehler illumination and a main feature of critical illumination are achieved using a novel illumination system. Koehler illumination is prealigned in the device by fixing the light source precisely on the entrance slit of the condenser. This allows the user to adjust a focus point on the sample, which is a useful feature 
of critical illumination, and is achieved when the condenser is aligned with the objective to find the focal point on the sample. Thus, Koehler illumination is initially fixed, and the CytoViva can then be adjusted (up or down) to find the proper position and size of an illuminated spot for critical illumination. Both Koehler and critical illumination are not generally achievable in traditional microscopy. The resulting high signal to noise ratio of CytoViva allows the user to observe previously obscured nondiffraction-limited optical effects. The resolution of conventional optical microscopy is limited by the wave nature of light and is conventionally defined by the Rayleigh criterion; this is commonly referred to as diffraction-limited resolution (limit $\sim 240 \mathrm{~nm}$ ). With CytoViva, nondiffraction-limited optical effects and an improved point spread function are produced that extend its resolution well beyond diffraction limits. ${ }^{58}$

\section{Sample specifics}

Samples were received as paraffin-embedded tissue sections mounted on standard glass microscope slides. A drop of type A immersion oil was placed on the section and then a coverslip was applied.

\section{Design}

When using this system, the general outline of experimentation involves compiling a complete sample set, ie, control (healthy) tissue and diseased tissue. Diseased tissue was imaged specifically for this research and examined manually for abnormalities. The abnormalities were imaged and a spectral library was created for each tissue. The spectral libraries were then systematically compared with each other until only the spectra unique to the sample were left. These libraries can be used to detect the presence of each disease in subsequent samples.

\section{Results}

Each disease caused a unique spectral shift in tissue. This spectral shift can be used to evaluate the presence of the same disease in future patients. The pathologic findings are shown under 100× magnification in the upper rows of Figures 3-7, and the spectral images from CytoViva are shown in the lower rows. All entities were displayed according to the proposed technique and a unique spectral library was formed for each entity. The technique was able to identify the same unique spectral library in the second sets of slides for the same disease. The experiment had 100\% efficiency for these diseases at least, and the two sets of examination slides that were used. A large clinical trial in the future will identify the advantages and disadvantages of the technique.

\section{Discussion}

We will not comment on the equipment used for diagnosis of lung cancer or the tissue samples necessary for this

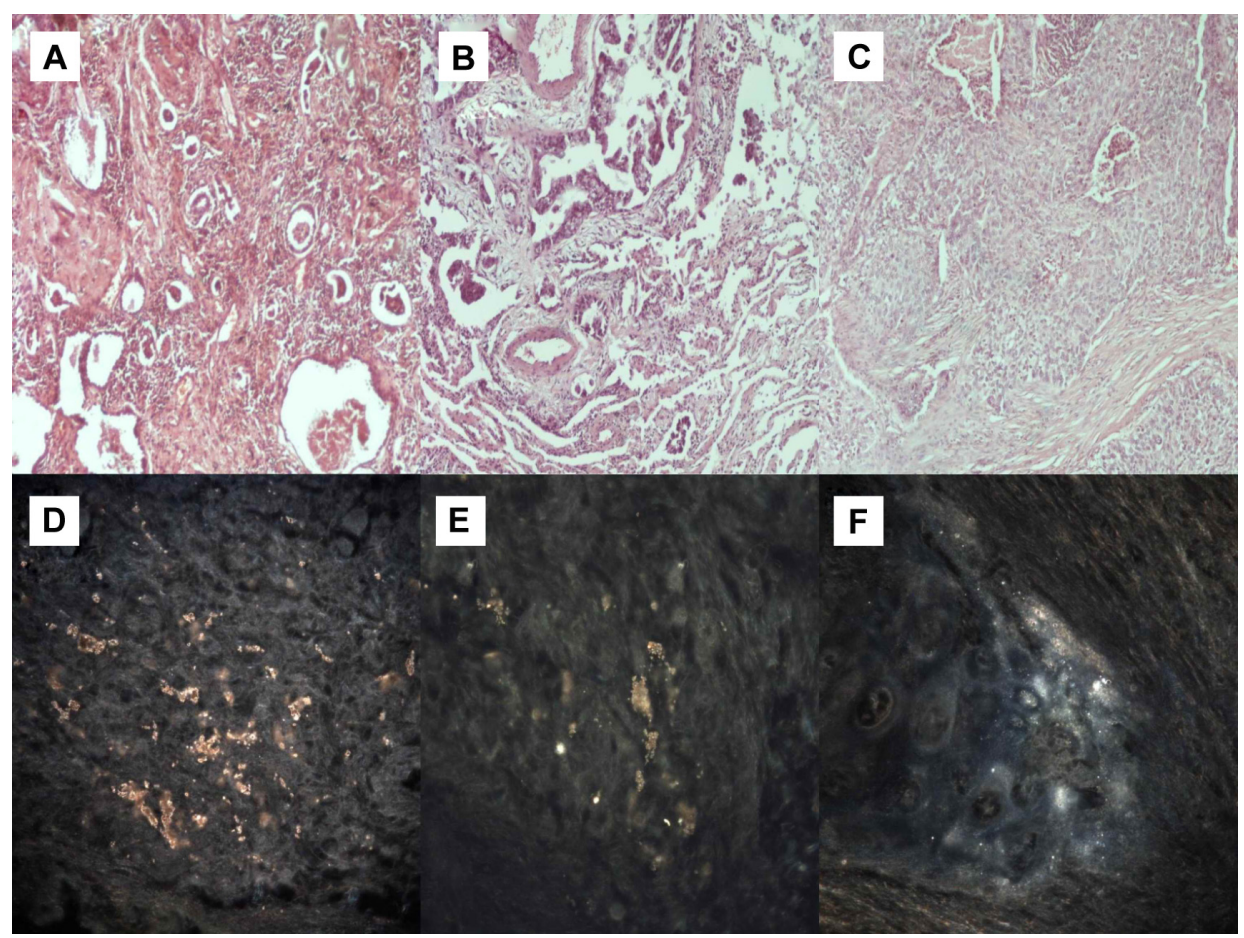

Figure 3 (A) Adenocarcinoma (microscopic observation 100x). (B) Adenocarcinoma with epidermal growth factor receptor mutation (microscopic observation I00x). (C) Squamous cell carcinoma (microscopic observation 100x). CytoViva ${ }^{\circledR}$ spectral imaging of (D) an adenocarcinoma, (E) an adenocarcinoma with epidermal growth factor receptor mutation, and $(\mathbf{F})$ a squamous cell carcinoma. 


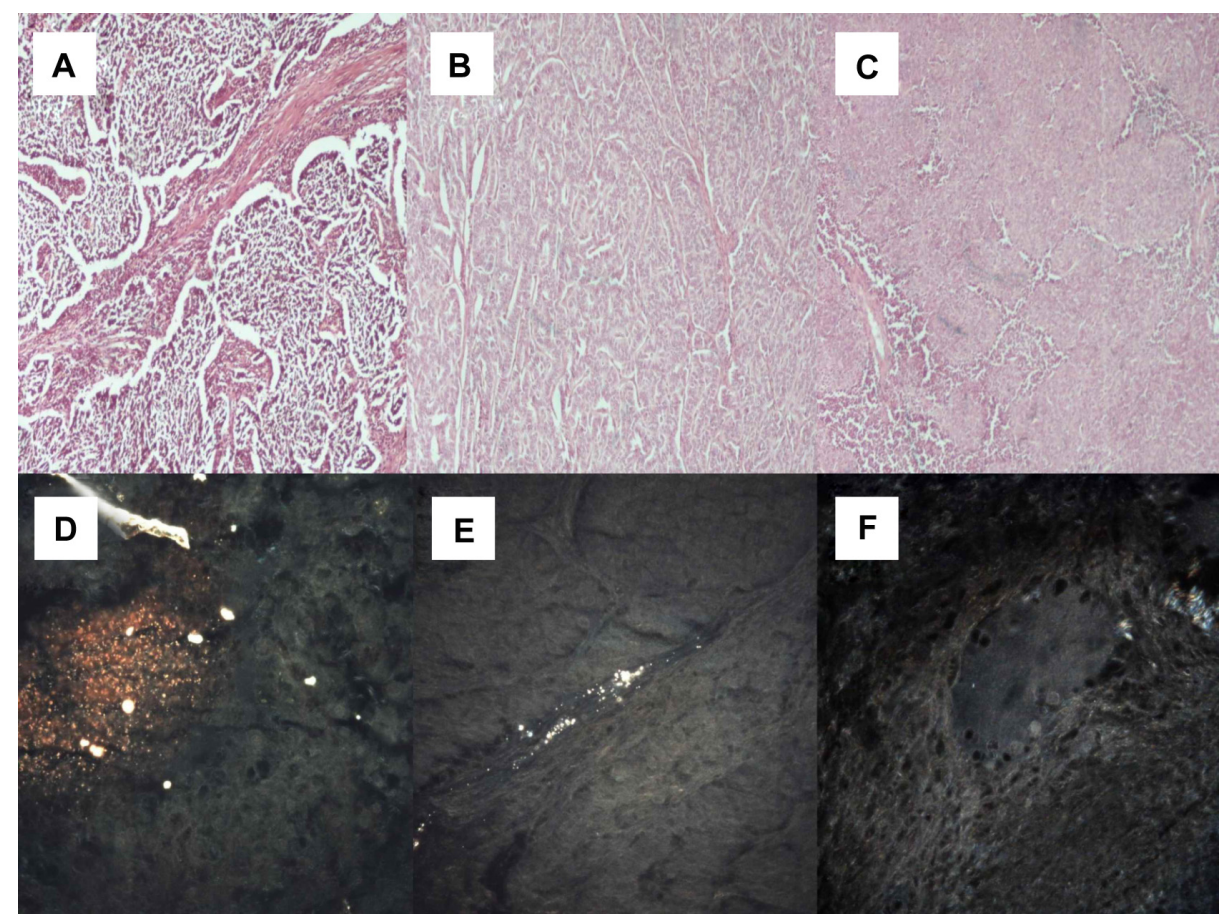

Figure 4 (A) Small cell neuroendocrine carcinoma (microscopic observation 100x). (B) Typical carcinoid tumor (microscopic observation I00x). (C) Thymoma (microscopic observation 100x). CytoViva ${ }^{\circledR}$ spectral imaging of (D) a small cell neuroendocrine carcinoma, (E) a typical carcinoid tumor, and (F) a thymoma.

because they have been evaluated previously and are accepted worldwide.$^{33}$ However, we should state that the equipment is expensive, a large number of samples can be examined in a short time, and in time, the initial expense covers the ongoing expense of the pathology laboratory. The novel technique described here is under evaluation, and only after a large trial has been performed will we be able to draw conclusions regarding its efficiency and limitations. The major limitation of our present study is its small sample size. There are currently several different methodologies used to

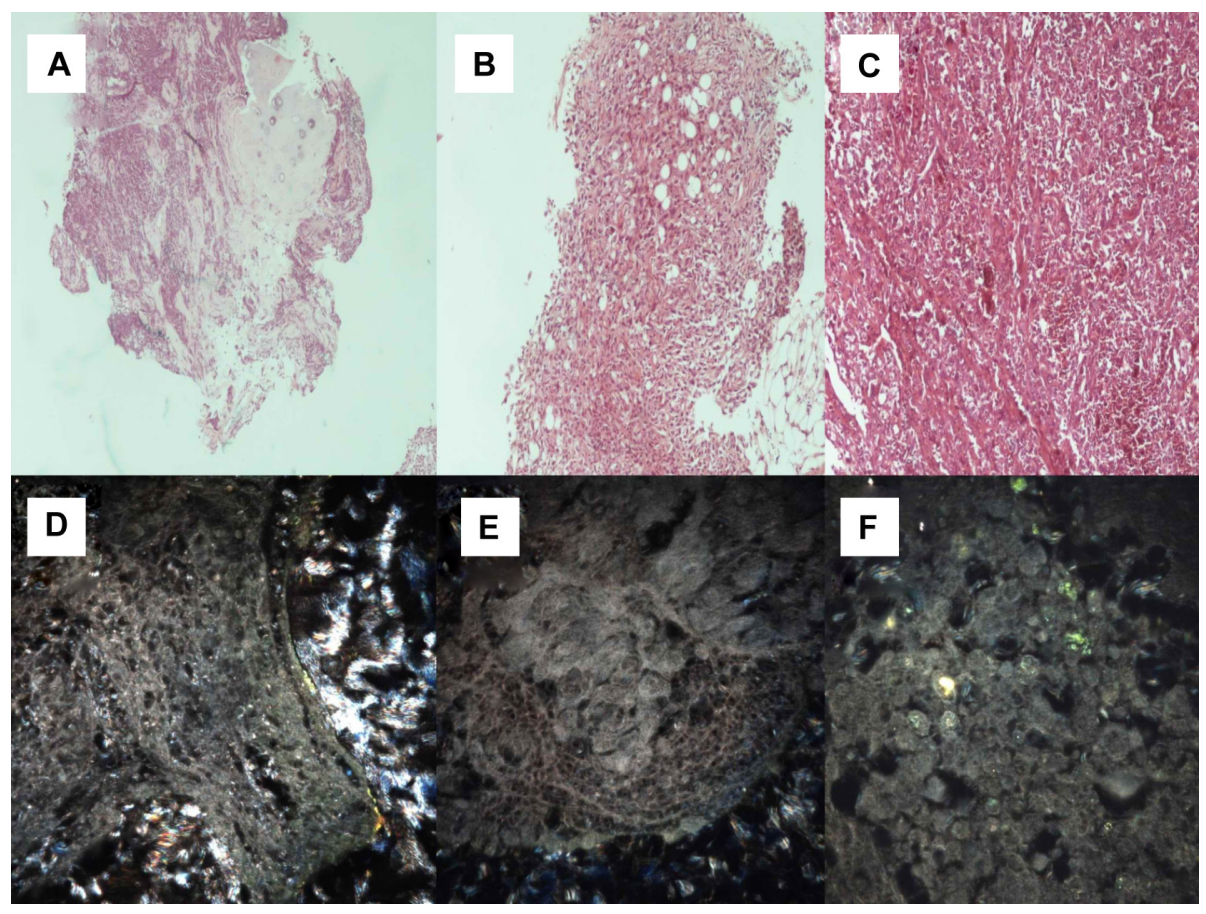

Figure 5 (A) Malt cell lymphoma (microscopic observation I00x). (B) Sarcomatoid mesothelioma (microscopic observation I00x). (C) Epithelioid mesothelioma (microscopic observation $100 \times)$. CytoViva ${ }^{\circledR}$ spectral imaging of (D) a malt cell lymphoma, (E) a sarcomatoid mesothelioma, and (F) an epithelioid mesothelioma. 


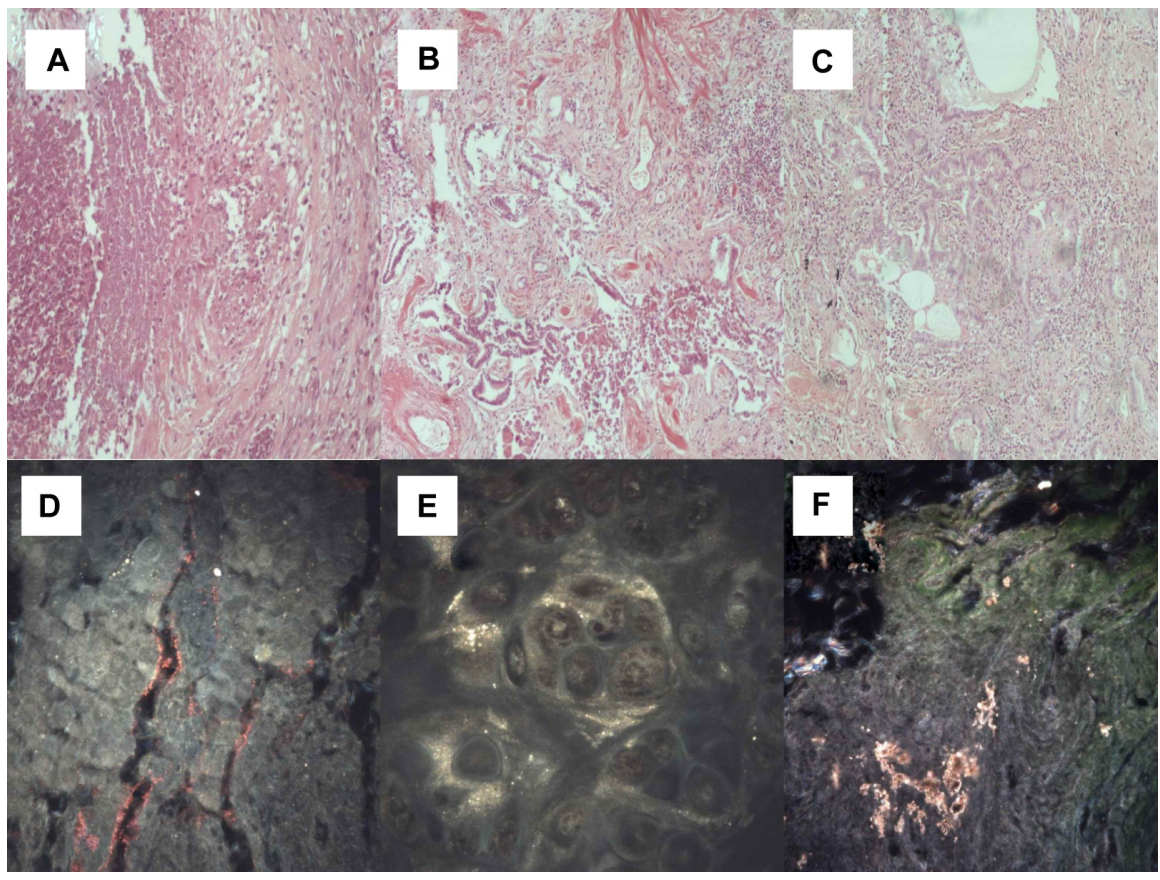

Figure 6 (A)Wegener's granulomatosis (microscopic observation I00x).(B) Usual interstitial pneumonia (microscopic observation I00 $\times$ ). (C) Nonspecific interstitial pneumonia (microscopic observation $100 \mu \mathrm{m}$ ). (D) CytoViva ${ }^{\circledR}$ spectral imaging of Wegener's granulomatosis, (E) usual interstitial pneumonia, and (F) nonspecific interstitial pneumonia.

display cells and tissue samples efficiently and to enhance the ones already used. In a study by Li et al, ${ }^{55}$ a Congo red-bovine serum albumin-gadolinium-diethylene triamine penta acetate magnetic resonance imaging probe was constructed and used to display individual senile plaques in a study of Alzheimer's disease. Exofacial protein thiols have been used as a route for internalization of gadolinium (III)based complexes for labeling of subcellular structures, such as endosomes seen on magnetic resonance imaging. ${ }^{49}$ Tc99 radiolabeling of adenoviral particles containing capsid

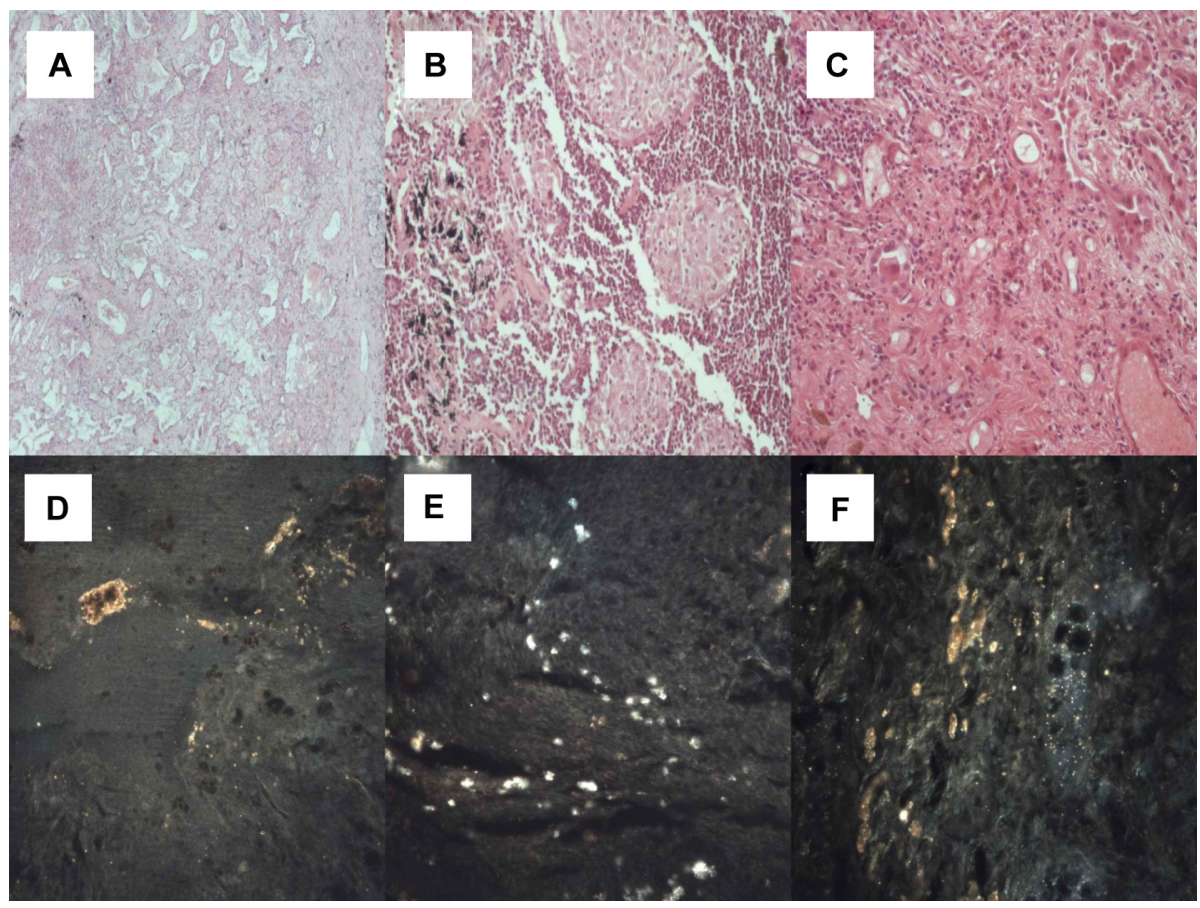

Figure 7 (A) Cryptogenic organizing pneumonia (microscopic observation 100x). (B) Sarcoidosis (microscopic observation 100x). (C) Interstitial pulmonary fibrosis (microscopic observation $100 \times$ ). CytoViva ${ }^{\circledR}$ spectral imaging of (D) cryptogenic organizing pneumonia, (E) sarcoidosis, and (F) interstitial pulmonary fibrosis. 
protein IX-human metallothionein in vivo has been used as a method of display for gene therapy. ${ }^{54} \mathrm{Ga} 68$ has been used to display bifunctional versions of a 1,2-[\{6-(carboxylato) pyridin-2-yl $\}$ methylamino] ethane (H2dedpa) scaffold for conjugation with a target vector. ${ }^{50}$ This method can also be used for imaging of the corresponding conjugates in gene therapy experiments. Breast carcinoma tissue expressing human epidermal growth factor receptor 2 has been efficiently displayed by radiolabeling DOTA-(GSG)-KCCYSL with ${ }^{111} \mathrm{In} .{ }^{42}$ This method can be used as a tumor-imaging agent or vehicle for cytotoxic agents and radionucleotides in tumors overexpressing human epidermal growth factor receptor 2. Two-photon imaging has been used in vivo to perform live imaging of p-myelin basic protein-enhanced green fluorescent protein-Escherichia coli nitroreductase during myelin repair. ${ }^{53}$ Near-infrared phosphorescent probes and live-cell fluorescence has been used for measurement of oxygen in single mammalian cells. ${ }^{52}$ A novel peptide sequence with nanomolar affinity for near infrared (benz) indolium fluorochromes has also been used as a site-specific protein labeling method. This peptide sequence is known as "IQ-tag" and is anticipated to have a variety of applications in drug development, cell tracking, site-specific protein imaging, and target identification. ${ }^{41}$ Infrared imaging of vascular dysfunction has been also done in sickle cell disease. ${ }^{39}$ Orthogonal polarization spectral imaging has also been used to assess quantitative changes in microvessels. This method enables noninvasive evaluation of tissue perfusion in preterm and term infants. ${ }^{44} \mathrm{~A}$ vessel catheter with optical coherence tomography has been constructed for accurate evaluation of structural information from developing vessels ${ }^{40}$ In a further study, ${ }^{18} \mathrm{~F}-\mathrm{ZW}-104$, a novel positron emission tomography radioligand, was developed to display central nicotinic acetylcholine receptors in baboons, ${ }^{59}$ and the results indicated that this new radioligand could be used in humans to study nicotinic acetylcholine receptors containing the $\beta 2$ subunit. Further, in a study by Muller et $\mathrm{al},{ }^{47}$ a novel optical high resolution system was developed to display adult cardiomyocytes. All these studies demonstrate materials that can be used to design a mold where two-dimensional and three-dimensional cell cultures can be proliferated.

Additional software was also developed, working either in stand-alone mode or plug-in mode. This represents not only an excellent methodology combining both the external materials necessary for a cell culture and also the methodology for efficient cell imaging. Nanobarcoded superparamagnetic iron oxide nanoparticles were developed and characterized by zeta potential, hyperspectral characteristics, and dynamic light imaging measurements. ${ }^{51}$ Cyanine dye 5 was used to label the nanobarcoded superparamagnetic iron oxide nanoparticles and then confocal microscopy was used to display the cellular uptake. In situ polymerase chain reaction was used to detect signals from nanobarcoded superparamagnetic iron oxide nanoparticles inside $\mathrm{HeLa}$ cells; however, minimal cellular uptake was observed with confocal microscopy. Time-lapse confocal imaging was used to observe fluorescently-labeled microglia in retinal explants from CX3CR 1 //GFP mice. ${ }^{46}$ This method can be used to display focal tissue injury efficiently ex vivo as well as the response to focal laser photocoagulation. Immunogold labeling, a spot fluorescence photolabeling method, was also used to demonstrate the absence of a lipid continuum between parasite membranes, Maurer's clefts, and the host membrane. ${ }^{45}$ Currently, a similar project using threedimensional optical projection tomographic microscopy is being developed by Visiongate to identify morphology unique to different cells. ${ }^{36,37}$ This new methodology is already able to identify cancer cells from expectorated human sputum with a very low false negative false rate. Results from a large ongoing study of this methodology in the early detection of lung cancer are awaited.

Three-dimensional tissue reconstruction using cryoimaging techniques has been investigated, allowing resolution at the micron level. Cancer cell migration was also investigated using this method in a glioma cancer cell model ${ }^{60}$ Further, novel chimeric proteins were constructed from human type II transmembrane proteins conjugated with in-frame red fluorescence protein. Transgenic cancer lines express these proteins, and metastasis of cancer cells has been observed using this methodology. ${ }^{43}$ Metastasis and visual targets of cancer cells were also seen using a dual multicolor fluorescent protein. ${ }^{38}$ Cancer cells were labeled with this novel protein, and trafficking of cancer cells inside vessels was able to be done.

Using CytoViva, we were able to create unique spectral libraries of lung cancer subtypes and benign diseases. The software recognizes only the spectral library. In the upper rows of Figures 3-7 we have included the "picture" that the pathologists recognize, while in the bottom rows we have included the "picture" that the CytoViva equipment recognizes. The software is still evolving, in that the software illustrates several "spots" or formations that are identical within the same tissue samples, eg, adenocarcinoma, squamous cell carcinoma, or sarcoidosis, but cannot identify whether these are vessels, fibrinous tissue, or interstitial fluid. Since we have provided information in the software based on examination by our own pathologists, which 
spectral library corresponds to which entity, (eg, adenocarcinoma with epidermal growth factor), each time after the first slide the software immediately identifies the spectral library of a new tissue sample with the same pathological entity, since the same library is recognized by the CytoViva software. The same occurs for every tissue slide that the spectral library has previously created and tagged. So, on its own, the equipment does not have the ability to identify tissue on an examination slide. However, if a series of spectral libraries are created from slides with several tissue samples and archived in the database of the equipment, then, with the appropriate validation, the technique could be used as a rapid on-site diagnostic tool for several types of tissue. Rapid on-site diagnosis of malignant disease is crucial for patients with lung cancer because decisions regarding treatment are based on it. Accurate staging is very important for appropriate decision-making regarding treatment of lung cancer, and evaluating the lymph nodes one by one during the diagnostic process is essential. Rapid on-site diagnosis can prevent excessive and unnecessary tissue sampling and thereby reduce comorbidity for patients.

A major limitation of this study was the inability to evaluate the technique in lymph node samples, because we had only acquired permission to obtain results concerning the feasibility of the technique. There are still questions to be answered, for example, whether the biopsy site within a lymph node or tumor plays a role in the creation of spectral imaging or if the method of biopsy provides different spectral imaging results. In the case of the "stop effect", the biopsy method certainly plays a crucial role in obtaining appropriate material for diagnosis ${ }^{61}$ (Figure 2C).

\section{Conclusion and future perspectives}

The software used for this equipment is now able to identify subsequent lung tissue specimens by introducing into the CytoViva apparatus a standard $1 \mathrm{~mm}$ glass slide with a \#1 coverslip carrying a $10 \mu \mathrm{m}$ lung tissue. Rapid onsite disease staging is essential for the patient with lung cancer. It remains for a larger series of lung tissue tests to be performed in order to investigate the sensitivity and specificity of this technique as a future on-site diagnostic tool and to obtain additional technical information. In our department, we have created a probe that is inserted through the working channel of the bronchoscope and has the ability to create a spectral library of any tissue it touches without the need for tissue sampling and preparation of slides for examination. However, a large clinical trial is necessary to investigate the strengths and weaknesses of this technique. Additionally, a large clinical trial in several diseases will identify if this technique is applicable for diagnosis in all tissues.

\section{Acknowledgments}

PZ would like to thank all the senior members and staff of CytoViva, Inc (Auburn, AL, USA) (http://www.cytoviva.

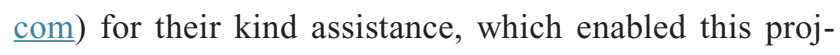
ect to be accomplished. LF developed the bronchoscope probe that creates the spectral library; Department of Interventional Pneumology, Ruhrlandklinik, West German Lung Center, University Hospital, University DuisburgEssen, Essen, Germany. The authors thank PZ (http://www. bizjournals.com/phoenix/news/2011/10/20/visiongate-lands2-million-in.html) and KZ (http://www.visiongate3d.com/ about/collaborators) who are collaborators of Visiongate Corporation in the project for early detection of lung cancer.

\section{Disclosure}

The authors have no relevant affiliations or financial involvement with any organization or entity with a financial interest in or financial conflict with the subject matter or materials discussed in this paper. This includes employment, consultancies, honoraria, stock ownership or options, expert testimony, grants or patents received or pending, or royalties.

\section{References}

1. Kaneda H, Yoshida T, Okamoto I. Molecularly targeted approaches herald a new era of non-small-cell lung cancer treatment. Cancer Manag Res. 2013;5:91-101.

2. Salama JK, Vokes EE. New radiotherapy and chemoradiotherapy approaches for non-small-cell lung cancer. J Clin Oncol. 2013;31:1029-1038.

3. Boutsikou E, Kontakiotis T, Zarogoulidis P, et al. Docetaxel-carboplatin in combination with erlotinib and/or bevacizumab in patients with nonsmall cell lung cancer. Onco Targets Ther. 2013;6:125-134.

4. Zarogoulidis K, Kontakiotis T, Hatziapostolou P, et al. A Phase II study of docetaxel and carboplatin in the treatment of non-small cell lung cancer. Lung Cancer. 2001;32:281-287.

5. Zarogoulidis K, Mylonaki E, Kakavelas P, et al. Topotecan-carboplatinetoposide combination as 1 st line treatment in patients with small cell lung cancer. Lung Cancer. 2009;66:226-230.

6. Shibuya M, Kogo M, Kurihara T, et al. [Analysis of the risk factors for severe neutropenia in advanced non-small cell lung cancer after the first course of chemotherapy with third-generation agents]. Yakugaku Zasshi. 2013;133:703-709. Japanese.

7. Zarogoulidis K, Papagiannis A, Ziogas E, et al. Management of chemotherapy-related anaemia with low-dose recombinant human erythropoietin in patients with small cell lung cancer. Eur J Cancer. 1997;33:2428-2431.

8. Zarogoulidis P, Chatzaki E, Hohenforst-Schmidt W, et al. Management of malignant pleural effusion by suicide gene therapy in advanced stage lung cancer: a case series and literature review. Cancer Gene Ther. 2012;19:593-600.

9. Zarogoulidis P, Petridis D, Ritzoulis C, et al. Establishing the optimal nebulization system for paclitaxel, docetaxel, cisplatin, carboplatin and gemcitabine: back to drawing the residual cup. Int J Pharm. 2013;453:480-487. 
10. Zarogoulidis P, Chatzaki E, Porpodis K, et al. Inhaled chemotherapy in lung cancer: future concept of nanomedicine. Int J Nanomedicine. 2012;7:1551-1572.

11. Zarogoulidis P, Eleftheriadou E, Sapardanis I, et al. Feasibility and effectiveness of inhaled carboplatin in NSCLC patients. Invest New Drugs. 2012;30:1628-1640.

12. Porpodis K, Karanikas M, Zarogoulidis P, et al. A case of typical pulmonary carcinoid tumor treated with bronchoscopic therapy followed by lobectomy. J Multidiscip Healthc. 2012;5:47-51.

13. Bolliger CT, Sutedja TG, Strausz J, Freitag L. Therapeutic bronchoscopy with immediate effect: laser, electrocautery, argon plasma coagulation and stents. Eur Respir J. 2006;27:1258-1271.

14. Zarogoulidis K, Eleftheriadou E, Kontakiotis T, et al. Long acting somatostatin analogues in combination to antineoplastic agents in the treatment of small cell lung cancer patients. Lung Cancer. 2012;76: 84-88.

15. Willers H, Azzoli CG, Santivasi WL, Xia F. Basic mechanisms of therapeutic resistance to radiation and chemotherapy in lung cancer. Cancer J. 2013;19:200-207.

16. Smith RA, Brooks D, Cokkinides V, Saslow D, Brawley OW. Cancer screening in the United States, 2013: a review of current American Cancer Society guidelines, current issues in cancer screening, and new guidance on cervical cancer screening and lung cancer screening. $C A$ Cancer J Clin. 2013;63:88-105.

17. Bunn PA Jr. Worldwide overview of the current status of lung cancer diagnosis and treatment. Arch Pathol Lab Med. 2012;136:1478-1481.

18. Darwiche K, Baumbach JI, Sommerwerck U, Teschler H, Freitag L. Bronchoscopically obtained volatile biomarkers in lung cancer. Lung. 2011;189:445-452.

19. Huttenberger D, Gabrecht T, Wagnieres G, et al. Autofluorescence detection of tumors in the human lung - spectroscopical measurements in situ, in an in vivo model and in vitro. Photodiagnosis Photodyn Ther. 2008;5:139-147.

20. Vallieres E, Shepherd FA, Crowley J, et al. The IASLC Lung Cancer Staging Project: proposals regarding the relevance of TNM in the pathologic staging of small cell lung cancer in the forthcoming (seventh) edition of the TNM classification for lung cancer. $J$ Thorac Oncol. 2009;4:1049-1059.

21. Chien CR, Yang ST, Chen CY, et al. Impact of the new lung cancer staging system for a predominantly advanced-disease patient population. J Thorac Oncol. 2010;5:340-343.

22. Arribalzaga EB. New tumor, node, metastasis staging system for lung cancer. J Thorac Oncol. 2009;4:1301.

23. Boffa DJ, Detterbeck FC, Smith EJ, et al. Should the 7th edition of the lung cancer stage classification system change treatment algorithms in non-small cell lung cancer? J Thorac Oncol. 2010;5:1779-1783.

24. Pepek JM, Chino JP, Marks LB, et al. How well does the new lung cancer staging system predict for local/regional recurrence after surgery? A comparison of the TNM 6 and 7 systems. J Thorac Oncol. 2011;6: 757-761.

25. Zarogoulidis K, Latsios D, Porpodis K, et al. New dilemmas in smallcell lung cancer TNM clinical staging. Onco Targets Ther. 2013;6: 539-547.

26. Russell PA, Wainer Z, Wright GM, Daniels M, Conron M, Williams RA. Does lung adenocarcinoma subtype predict patient survival? A clinicopathologic study based on the new International Association for the Study of Lung Cancer/American Thoracic Society/European Respiratory Society international multidisciplinary lung adenocarcinoma classification. J Thorac Oncol. 2011;6:1496-1504.

27. Lee $\mathrm{HJ}$, Lee $\mathrm{CH}$, Jeong YJ, et al. IASLC/ATS/ERS International Multidisciplinary Classification of Lung Adenocarcinoma: novel concepts and radiologic implications. J Thorac Imaging. 2012;27:340-353.

28. Travis WD, Brambilla E, Noguchi M, et al. Diagnosis of lung cancer in small biopsies and cytology: implications of the 2011 International Association for the Study of Lung Cancer/American Thoracic Society/ European Respiratory Society classification. Arch Pathol Lab Med. 2013;137:668-684.
29. Travis WD, Brambilla E, Noguchi M, et al. Diagnosis of lung adenocarcinoma in resected specimens: implications of the 2011 International Association for the Study of Lung Cancer/American Thoracic Society/European Respiratory Society classification. Arch Pathol Lab Med. 2013;137:685-705.

30. Kimbrell HZ, Gustafson KS, Huang M, Ehya H. Subclassification of non-small cell lung cancer by cytologic sampling: a logical approach with selective use of immunocytochemistry. Acta Cytol. 2012;56: 419-424.

31. Brocken P, van der Heijden HF, Dekhuijzen PN, Peters-Bax L, de Geus-Oei LF. High performance of F-fluorodeoxyglucose positron emission tomography and contrast-enhanced CT in a rapid outpatient diagnostic program for patients with suspected lung cancer. Respiration. Epub April 16, 2013.

32. Silvestri GA, Gonzalez AV, Jantz MA, et al. Methods for Staging NonSmall Cell Lung Cancer: Diagnosis and Management of Lung Cancer. 3rd ed. American College of Chest Physicians evidence-based clinical practice guidelines. Chest. 2013;143(Suppl 5):e211S-e250S.

33. Block MI. Endobronchial ultrasound for lung cancer staging: how many stations should be sampled? Ann Thorac Surg. 2010;89:1582-1587.

34. Freitag L. Flexible contra starre Bronchoskopie für die Implantation von Prothesen tracheobronchial (Stents). Pro starre Bronchoskopie [Flexible contra rigid bronchoscopy for implantation of tracheobronchial prostheses (stents). Pro rigid bronchoscopy]. Pneumologie. 1997;51:255-257. German.

35. Wohlschlager J, Darwiche K, Ting S, et al. "Rapid on-site evaluation" (ROSE) in der zytologischen Diagnostik von Lungen- und Mediastinalerkrankungen [Rapid on-site evaluation (ROSE) in cytological diagnostics of pulmonary and mediastinal diseases]. Pathologe. 2012;33:308-315. German.

36. Meyer MG, Fauver M, Rahn JR, et al. Automated cell analysis in 2D and 3D: a comparative analysis. Pattern Recognit. 2009;42:141-146.

37. Rahn JR, Meyer MG, Patten FW, Neumann T, Nelson AC. Threedimensional imaging of single isolated cell nuclei using optical projection tomography. Opt Express. 2005;13:4210-4223.

38. Yamamoto N, Tsuchiya H, Hoffman RM. Tumor imaging with multicolor fluorescent protein expression. Int J Clin Oncol. 2011;16:84-91.

39. Gorbach AM, Ackerman HC, Liu WM, et al. Infrared imaging of nitric oxide-mediated blood flow in human sickle cell disease. Microvasc Res. 2012;84:262-269.

40. Gurjarpadhye AA, Whited BM, Sampson A, et al. Imaging and characterization of bioengineered blood vessels within a bioreactor using free-space and catheter-based OCT. Lasers Surg Med. 2013;45: 391-400.

41. Kelly KA, Carson J, McCarthy JR, Weissleder R. Novel peptide sequence ("IQ-tag") with high affinity for NIR fluorochromes allows protein and cell specific labeling for in vivo imaging. PLoS One. 2007;2:e665.

42. Kumar SR, Quinn TP, Deutscher SL. Evaluation of an 111 In-radiolabeled peptide as a targeting and imaging agent for ErbB-2 receptor expressing breast carcinomas. Clin Cancer Res. 2007;13:6070-6079.

43. Winnard PT Jr, Kluth JB, Kato Y, Artemov D, Raman V. Development of novel chimeric transmembrane proteins for multimodality imaging of cancer cells. Cancer Biol Ther. 2007;6:1889-1899.

44. Genzel-Boroviczeny O, Strotgen J, Harris AG, Messmer K, Christ F. Orthogonal polarization spectral imaging (OPS): a novel method to measure the microcirculation in term and preterm infants transcutaneously. Pediatr Res. 2002;51:386-391.

45. Hanssen E, Sougrat R, Frankland S, et al. Electron tomography of the Maurer's cleft organelles of Plasmodium falciparum-infected erythrocytes reveals novel structural features. Mol Microbiol. 2008;67: 703-718.

46. Lee JE, Liang KJ, Fariss RN, Wong WT. Ex vivo dynamic imaging of retinal microglia using time-lapse confocal microscopy. Invest Ophthalmol Vis Sci. 2008;49:4169-4176.

47. Muller O, Tian Q, Zantl R, Kahl V, Lipp P, Kaestner L. A system for optical high resolution screening of electrical excitable cells. Cell Calcium. 2010;47:224-233. 
48. Saba W, Valette H, Granon S, et al. [18F]ZW-104, a new radioligand for imaging alpha2-alpha3-alpha4/beta2 central nicotinic acetylcholine receptors: Evaluation in mutant mice. Synapse. 2010;64:570-572.

49. Digilio G, Menchise V, Gianolio E, et al. Exofacial protein thiols as a route for the internalization of $\mathrm{Gd}(\mathrm{III})$-based complexes for magnetic resonance imaging cell labeling. J Med Chem. 2010;53:4877-4890.

50. Boros E, Ferreira CL, Yapp DT, et al. RGD conjugates of the H2dedpa scaffold: synthesis, labeling and imaging with 68Ga. Nucl Med Biol. A2012;39:785-794.

51. Eustaquio T, Leary JF. Nanobarcoding: detecting nanoparticles in biological samples using in situ polymerase chain reaction. Int $J$ Nanomedicine. 2012;7:5625-5639.

52. O'Riordan TC, Fitzgerald K, Ponomarev GV, et al. Sensing intracellular oxygen using near-infrared phosphorescent probes and live-cell fluorescence imaging. Am J Physiol Regul Integr Comp Physiol. 2007;292:R1613-R1620.

53. Kaya F, Mannioui A, Chesneau A, et al. Live imaging of targeted cell ablation in Xenopus: a new model to study demyelination and repair. J Neurosci. 2012;32:12885-12895.

54. Mathis JM, Bhatia S, Khandelwal A, et al. Genetic incorporation of human metallothionein into the adenovirus protein IX for non-invasive SPECT imaging. PLoS One. 2011;6:e16792.
55. Li S, He H, Cui W, et al. Detection of Abeta plaques by a novel specific MRI probe precursor CR-BSA-(Gd-DTPA)n in APP/PS1 transgenic mice. Anat Rec (Hoboken). 2010;293:2136-2143.

56. Sun X, Niu G, Yan Y, et al. Phage display-derived peptides for osteosarcoma imaging. Clin Cancer Res. 2010;16:4268-4277.

57. Zarogoulidis P, Hohenforst-Schmidt W, Darwiche K, et al. 2-diethylaminoethyl-dextran methyl methacrylate copolymer nonviral vector: still a long way toward the safety of aerosol gene therapy. Gene Ther. 2013;20:1022-1028.

58. Vainrub A, Pustovyy O, Vodyanoy V. Resolution of $90 \mathrm{~nm}$ (lambda/5) in an optical transmission microscope with an annular condenser. $\mathrm{Opt}$ Lett. 2006;31:2855-2857.

59. Valette H, Xiao Y, Peyronneau MA, et al. 18F-ZW-104: a new radioligand for imaging neuronal nicotinic acetylcholine receptors - in vitro binding properties and PET studies in baboons. J Nucl Med. 2009;50:1349-1355.

60. Burden-Gulley SM, Qutaish MQ, Sullivant KE, et al. Novel cryo-imaging of the glioma tumor microenvironment reveals migration and dispersal pathways in vivid three-dimensional detail. Cancer Res. 2011;71:5932-5940.

61. Darwiche K, Wagner M, Theegarten D. Aktueller Stellenwert des endobronchialen Ultraschalls (EBUS) [Current value of endobronchial ultrasound (EBUS)]. Pneumologie. 2011;65:537-548. German.
International Journal of Nanomedicine

\section{Publish your work in this journal}

The International Journal of Nanomedicine is an international, peerreviewed journal focusing on the application of nanotechnology in diagnostics, therapeutics, and drug delivery systems throughout the biomedical field. This journal is indexed on PubMed Central, MedLine, CAS, SciSearch ${ }^{\circledR}$, Current Contents ${ }^{\circledR} /$ Clinical Medicine,

\section{Dovepress}

Journal Citation Reports/Science Edition, EMBase, Scopus and the Elsevier Bibliographic databases. The manuscript management system is completely online and includes a very quick and fair peer-review system, which is all easy to use. Visit http://www.dovepress.com/ testimonials.php to read real quotes from published authors. 